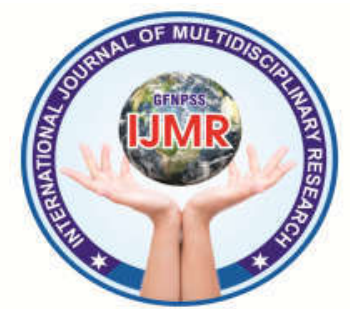

ISSN (0): 2582-693X

Original Article

\title{
COMPARISON OF SKELETAL AND ALVEOLAR MEASUREMENTS IN DIFFERENT SKELETAL PATTERNS USING PANOROMIC RADIOGRAPH AND LATERAL CEPHALOGRAM IN SOUTH RAJASTHAN POPULATION
}

\section{DR NEERAL BARTHUNIA ${ }^{1}$ DR HAJIRA BHANU.S ${ }^{2}$ DRRONIK NARAYANI ${ }^{3}$ DR RUGHANI DARSH ANIL ${ }^{4}$ DR RISHI MANGAL ${ }^{5}$}

${ }^{1}$ Professor and Head of the Department of Orthodontics and Dentofacial Orthopaedics, Daswani dental college and Reaserch Center.

${ }^{2}$ Post graduate student, Department of Orthodontics and Dentofacial Orthopaedics, Daswani dental college and Reaserch Center.

${ }^{3}$ Post graduate student, Department of Orthodontics and Dentofacial Orthopaedics, Daswani dental college and Reaserch Center.

${ }^{4}$ Post graduate student, Department of Orthodontics and Dentofacial Orthopaedics, Daswani dental college and Reaserch Center.

${ }^{5}$ Reader, Department of Orthodontics and Dentofacial Orthopaedics, Daswani dental college and Reaserch Center.

Corresponding Email: orthoneera15@yahoo.co.in, haji.bhanu.com@gmail.com, roniknaryani10@gmail.com, darsh7.dr@gmail.com, rishimangalpdc@gmail.com

\section{ABSTRACT:}

Aim:The aim of this study is to determine the skeletal and alveolar measurement in different skeletal patterns using panaromic radiograph and lateral cephalogram

Objective:To find correlations between orthopantomographs and lateral cephalogram linear and angular measurements

To find significant difference between the values of horizontal, vertical and average growth pattern

To check the possible application and reliability of OPG to determine treatment plan

\section{Methodology:}

The study was set up in Daswani Dental College \& Research Centre, Ranpur, Kota. we included 90 untreated adults of south rajasthan population visiting the Department of Orthodontics And Dentofacial Orthopaedics will be included in the study as per the inclusion and exclusion criteria

\section{Result:}

There is a statistically significant relationship between opg and lateral cephalogram

Keyword: Skeletal and Alveolar,Skeletal Patterns,Panoromic Radiograph and Lateral Cephalogram 


\section{INTRODUCTION}

The advent of lateral cephalogram in 1931 by Broadbent in United States and Hofrath in Germany provided both a clinical and a research tool to assess the underlying skeletal disproportions the discovery of panoramic technique by Paatero in 1952, dentists have used it in a variety of dental specialties. Panoramic radiography provides the clinician with a comprehensive view of maxillofacial complex with relatively reduced radiation exposure ${ }^{[1]}$.despite the fact that newer techniques such as computed tomography(CT) and magnetic resonance imaging (MRI) can provide more accurate information, panoramic radiography is more commonly performed,as it produces less radiation compared to $\mathrm{CT}$ and $\mathrm{MRI}^{[4]}$.

Cephalograms and orthopantom ogram are routinely taken for every orthodontic patient. The goal of cephalometric analysis is to evaluate the horizontal and vertical relationship of 5 major functional components of the face: cranium and cranial base, skeletal maxilla, skeletal mandible, the maxillary dentition and alveolar process and the mandibular dentition and alveolar process. The vertical relationship of these structures is as important as the horizontal relations, as the treatment plan as well as the outcome is affected by the vertical relationships and the growth pattern of the patient. The gonial angle is an important angle of the craniofacial complex. ${ }^{[3]}$

To analyze morphology and treatment effects, the most commonly used radiographs are lateral and posteroanterior cephalograms, oblique mandibular radiographs, and orthopantomograms . The cephalometric analysis on a lateral cephalogram consists of a combination of distances and angles, constructed from craniofacial anatomical landmarks (Sekiguchi and Savara, 1972; Athanasiou, 1995; Trpkova et al., 1997).

There are three basic types of facial vertical growth pattern: hypo-divergent , normo-divergent, and hyper-divergent growth patterns. ${ }^{[6]}$ The hyper-divergent pattern is typified by excessive vertical facial growth. It is usually associated (SN)-mandibular plane (MP) angle, gonial angle, and maxillary/mandibular planes angle. The hypo-divergent pattern is typified by reduced vertical growth. It is usually accompanied by deep anterior overbite, reduced facial heights, and reduced SN-MP angle. ${ }^{[8]}$ Between the two types lays the normo-divergent facial 


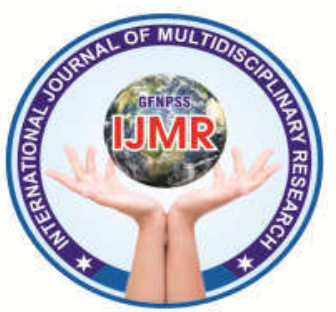

growth pattern.with anterior open bite and

EXCLUSION CRITERIA

an increased sella-nasion.

\section{MATERIALS AND METHOD SOURCE OF THE DATA}

The study is set up in Daswani Dental College \&Research Centre, Ranpur, Kota. This study included 90 untreated adults of south rajasthan population visiting the Department of Orthodontics And Dentofacial Orthopaedics as per inclusion criteria.

Total of 90 adults falling in the age group of 16-35 years old were taken respectively.

\section{PATIENT SELECTION CRITERIA:}

The selection criteria of this study includes:-

1. The subjects wereall from south rajasthan population

2. Well-nourished and free ofany known systemic disease.

3. None underwent neither previous orthodontic treatment nor extraction of any permanent teeth.

4. Normal growth and development.

5. No previous history of trauma or injury to theface regions.

6. The patients and parental consent was taken before taking radiographs.

7. Individuals between 16-35 years.

- Previous orthodontic treatment

- Edentulous spaces, history of extraction

- History of Facial trauma.

\section{METHODOLOGY}

- Lateral cephalogram and panoramic radiography tracing will be done to measure:

- AFH (mm) Anterior face height (LCR): vertical distance between Gn and the H-line

- AFH (mm) Anterior face height (PR): distance between $\mathrm{Ht}$ and $\mathrm{m}$

- PFH (mm) Posterior face height (LCR): vertical distance between

Gò and the H-line PFH (mm) Posterior face height (PR): distance between $\mathrm{Hv}$ and Gò

- ML/RL (degree) Gonial angle: angle between the reference lines ML and RL

- $\mathrm{ML} / \mathrm{H}$ (degree) Mandibular plane angle: angle between the reference lines $\mathrm{ML}$ and $\mathrm{H}$

- $\mathrm{NL} / \mathrm{H}$ (degree) Maxillary plane angle: angle between the reference lines $\mathrm{NL}$ and $\mathrm{H}$

- ML/NL (degree) Interjaw-base angle: angle between the reference lines ML and NL

- AHMx (mm) Anterior maxillary height (LCR): vertical distance between al-is and NL

- AHMx (mm) Anterior maxillary height (PR): distance between al-is and $\mathrm{Sp}$ 


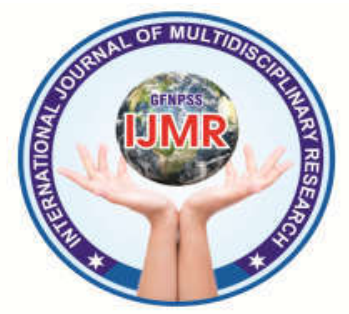

- PHMx (mm) Posterior maxillary height: vertical distance between al-ms and NL

- AHMn (mm) Anterior mandibular height (LCR): vertical distance between al-ii and ML AHMn (mm) Anterior mandibular height (PR): distance between al-ii and $\mathrm{m}$

- PHMn (mm) Posterior mandibular height: vertical distance between al-mi and ML

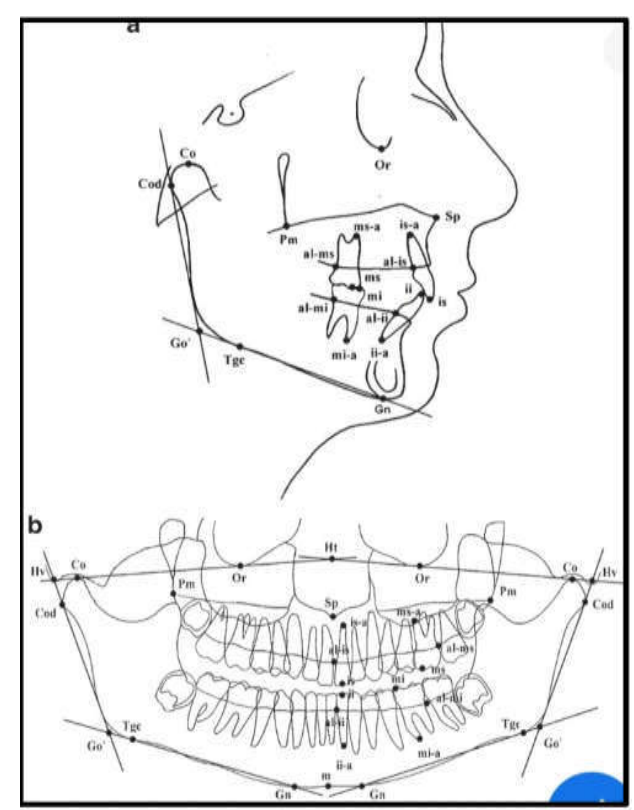

- Statistical analysis done and results evaluated further to correlate skeletal and alveolar measurements .

\section{RESULT:}

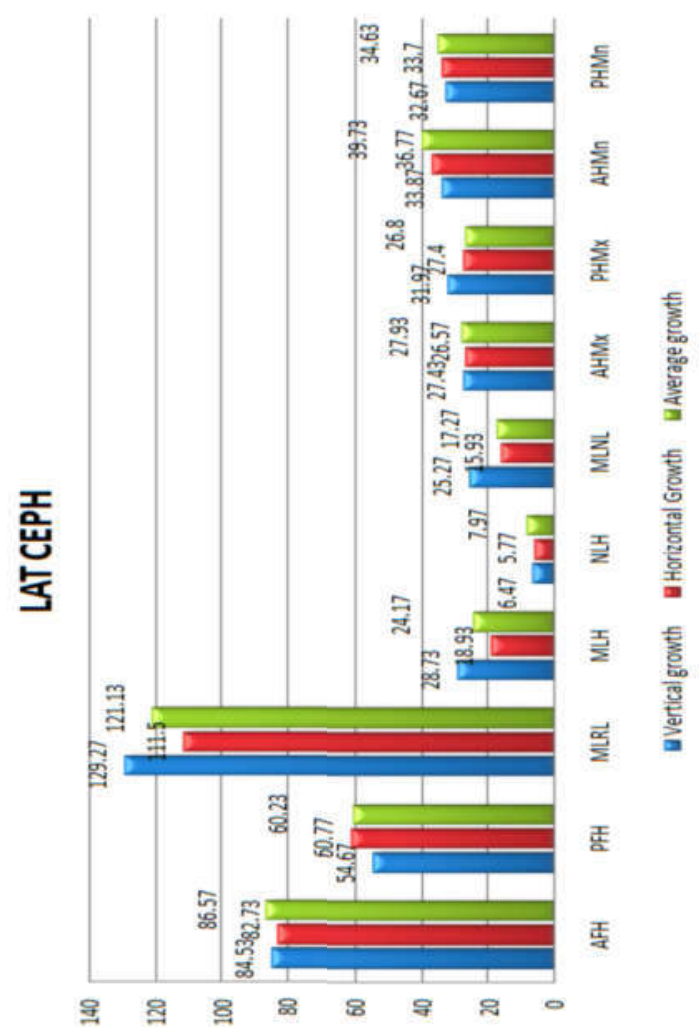

\begin{tabular}{|c|c|c|c|c|c|c|}
\hline \multicolumn{7}{|c|}{ ANOVA } \\
\hline & & Sum of Squares & df & Mean Square & F & Sig. \\
\hline \multirow[t]{3}{*}{ LAFH } & Between Groups & 220.689 & 2 & 110.344 & 2.860 & .063 \\
\hline & Within Groups & 3356.700 & 87 & 38.583 & & \\
\hline & Total & 3577.389 & 89 & & & \\
\hline \multirow[t]{3}{*}{ LPFH } & Between Groups & 684.822 & 2 & 342.411 & 7.338 & .001 \\
\hline & Within Groups & 4059.400 & 87 & 46.660 & & \\
\hline & Total & 4744.222 & 89 & & & \\
\hline \multirow[t]{3}{*}{ LMLRL } & Between Groups & 4746.067 & 2 & 2373.033 & 110.472 & .000 \\
\hline & Within Groups & 1868.833 & 87 & 21.481 & & \\
\hline & Total & 6614.900 & 89 & & & \\
\hline \multirow[t]{3}{*}{ LMLH } & Between Groups & 1442.822 & 2 & 721.411 & 22.023 & .000 \\
\hline & Within Groups & 2849.900 & 87 & 32.757 & & \\
\hline & Total & 4292.722 & 89 & & & \\
\hline \multirow{3}{*}{ LNLH } & Between Groups & 75.800 & 2 & 37.900 & 1.662 & 196 \\
\hline & Within Groups & 1983.800 & 87 & 22.802 & & \\
\hline & Total & 2059.600 & 89 & & & \\
\hline \multirow[t]{3}{*}{ LMLNL } & Between Groups & 1528.889 & 2 & 764.444 & 17.055 & .000 \\
\hline & Within Groups & 3899.600 & 87 & 44.823 & & \\
\hline & Total & 5428.489 & 89 & & & \\
\hline \multirow[t]{3}{*}{ LAHMx } & Between Groups & 28.689 & 2 & 14.344 & 1.364 & .261 \\
\hline & Within Groups & 914.600 & 87 & 10.513 & & \\
\hline & Total & 943.289 & 89 & & & \\
\hline \multirow[t]{3}{*}{ LPHMx } & Between Groups & 479.089 & 2 & 239.544 & 4.029 & .021 \\
\hline & Within Groups & 5172.967 & 87 & 59.459 & & \\
\hline & Total & 5652.056 & 89 & & & \\
\hline \multirow[t]{3}{*}{ LAHMn } & Between Groups & 516.289 & 2 & 258.144 & 5.044 & .008 \\
\hline & Within Groups & 4452.700 & 87 & 51.180 & & \\
\hline & Total & 4968.989 & 89 & & & \\
\hline \multirow[t]{3}{*}{ LPHMn } & Between Groups & 58.067 & 2 & 29.033 & 2.722 & .071 \\
\hline & Within Groups & 927.933 & 87 & 10.666 & & \\
\hline & Total & 986.000 & 89 & & & \\
\hline
\end{tabular}


We can see that the significance value is which is below 0.05 . and, therefore, there is a statistically significant difference in the mean of different growth on $\mathrm{PFH}$, MLRL, MLH, MLNL, PHMS, AHMn on LAT CEPH.

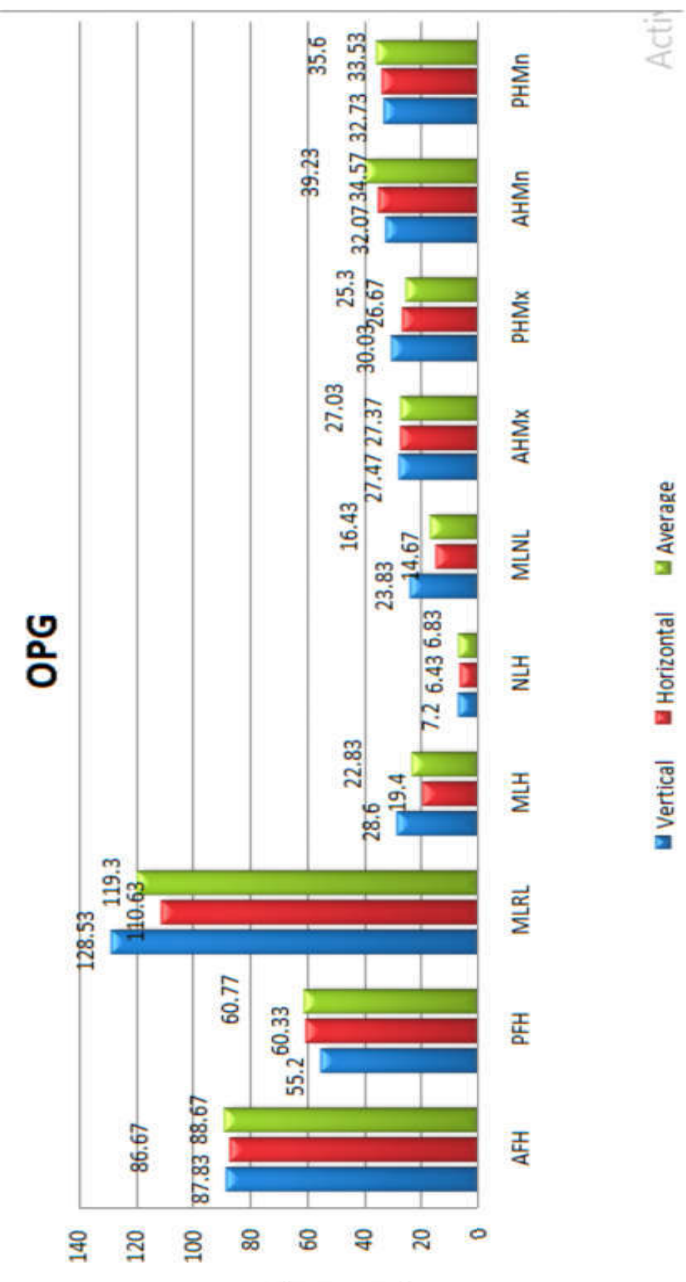

\begin{tabular}{|c|c|c|c|c|c|c|}
\hline \multicolumn{7}{|c|}{ ANOVA } \\
\hline & & Sum of Squares & df & Mean Square & $\mathrm{F}$ & Sig. \\
\hline \multirow[t]{3}{*}{ AFH } & Between Groups & 60.556 & 2 & 30.278 & .654 & .522 \\
\hline & Within Groups & 4027.500 & 87 & 46.293 & & \\
\hline & Total & 4088.056 & 89 & & & \\
\hline \multirow[t]{3}{*}{ PFH } & Between Groups & 575.267 & 2 & 287.633 & 6.546 & .002 \\
\hline & Within Groups & 3822.833 & 87 & 43.941 & & \\
\hline & Total & 4398.100 & 89 & & & \\
\hline \multirow[t]{3}{*}{ MLRL } & Between Groups & 4807.756 & 2 & 2403.878 & 157.633 & .000 \\
\hline & Within Groups & 1326.733 & 87 & 15.250 & & \\
\hline & Total & 6134.489 & 89 & & & \\
\hline \multirow[t]{3}{*}{ MLH } & Between Groups & 1296.822 & 2 & 648.411 & 24.020 & .000 \\
\hline & Within Groups & 2348.567 & 87 & 26.995 & & \\
\hline & Total & 3645.389 & 89 & & & \\
\hline \multirow[t]{3}{*}{$\mathrm{NLH}$} & Between Groups & 8.822 & 2 & 4.411 & .192 & .825 \\
\hline & Within Groups & 1996.333 & 87 & 22.946 & & \\
\hline & Total & 2005.156 & 89 & & & \\
\hline \multirow[t]{3}{*}{ MLNL } & Between Groups & 1419.089 & 2 & 709.544 & 18.503 & .000 \\
\hline & Within Groups & 3336.200 & 87 & 38.347 & & \\
\hline & Total & 4755.289 & 89 & & & \\
\hline \multirow[t]{3}{*}{ AHMx } & Between Groups & 3.089 & 2 & 1.544 & .113 & .893 \\
\hline & Within Groups & 1189.400 & 87 & 13.671 & & \\
\hline & Total & 1192.489 & 89 & & & \\
\hline \multirow[t]{3}{*}{ PHMx } & Between Groups & 356.067 & 2 & 178.033 & 3.605 & .031 \\
\hline & Within Groups & 4295.933 & 87 & 49.379 & & \\
\hline & Total & 4652.000 & 89 & & & \\
\hline \multirow{3}{*}{$\underset{\mathrm{N}}{\mathrm{AHM}}$} & Between Groups & 793.889 & 2 & 396.944 & 9.905 & .000 \\
\hline & Within Groups & 3486.600 & 87 & 40.076 & & \\
\hline & Total & 4280.489 & 89 & & & \\
\hline \multirow{3}{*}{$\begin{array}{c}\text { PHM } \\
\mathrm{N}\end{array}$} & Between Groups & 131.289 & 2 & 65.644 & 7.691 & .001 \\
\hline & Within Groups & 742.533 & 87 & 8.535 & & \\
\hline & Total & 873.82 .2 & 89 & & & \\
\hline
\end{tabular}

We can see that the significance value is which is below 0.05. and, therefore, there is a statistically significant difference in the mean of different growth on PFH, MLRL, MLH, MLNL, PHMS, AHMn, PHMn on OPG.

\section{DISCUSSION:}

The goal of this study was to correlate linear and angular measurements of opg and lateral cephalogram determining its potential for evaluating craniofacial specifications. Even though there are too number of published articles on magnification and image distortion in panoramic radiographs, there are only few 


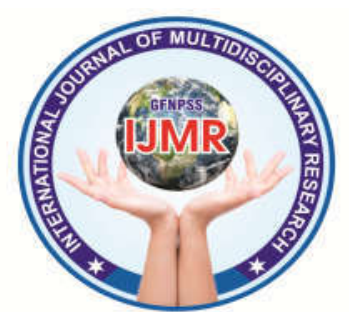

studies which involves use of panoramic radiographs in evaluating dentoskeletal specifications and gonial angle measurements. PR was recently proved to be a convenient tool for daignosing information on systemic diseases. It appears to be very useful for diagnosing osteoporosis ${ }^{[37-45]}$ and for identifying and evaluating cervical anomalies ${ }^{[46-48]}$

Mattila et al. ${ }^{[24]}$ They took measurements of gonial angle on cephalograms, OPG and dried skulls and concluded that the measurements on OPG for right and left gonial angles conform to the angles measured on dry skulls and concluded that means of the measurements made on cephalograms and OPG are more accurate. The present study shows the same In different growth patterns, it was seen that gonial angle and ramus height showed the highest correlation between the two radiographs.

Kurt et al. ${ }^{[51]}$ used OPGs to evaluate mandibular asymmetry in Class II subdivision malocclusion patients by measuring condylar, ramal, condylar-ramal asymmetry index values and gonial angle measurements. They concluded that acceptable results can also be achieved with the help of panoramic radiographs. radiographs was, they are non-invasive, favorable cost-benefit relationship and we can expose subjects to a relatively low dose of radiations.

$$
\text { Ongkosuwito et al. (2009) })^{[3]}
$$

concluded that an OPG is as reliable as a lateral cephalogram for linear measurements of the mandible, i.e., condylion-gonion, gonion-menton and condylion-menton.

In this study lateral ceph shows that the significance value which is below 0.05 and there is a statistically significant difference in the mean of different growth on PFH,MLRL,MLH,MLNL,PHMS,AHMn

On comparing horizontal growth patient with vertical and average growth

-vertical growth patient shows significant difference on PFH,MLRL,MLH,MLNL,

-Average growth patient shows significant difference on MLRL,MLH,

On comparing vertical growth patient with horizontal and average growth

-horizontal growth patient shows significant difference on PFH,MLRL,MLH,MLNL,

-Average growth patient shows significant difference on PFH, MLNL, MLH, MLRL, PHMx, AHMn

On comparing average growth patient with horizontal and vertical growth They added advantages of panoramic 


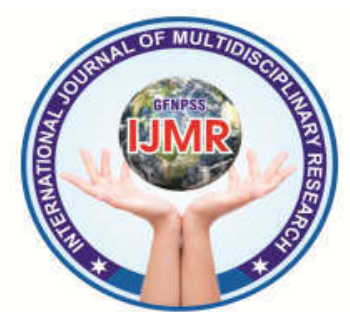

-horizontal growth patient shows between overbite differences that result significant difference on MLRL,MLH, from habits or true skeletal discrepancies.

-vertical growth patient shows significant difference on PFH, MLRL, MLH, MLNL, PHMx, AHMn

The Gonial Angle in PR is based on tomography, while the GA on LCR is a simple lateral view. Therefore, the GA on PR might not represent all data present on LCR. Thus, the LCR might provide a clearer GA angle. On PR, the form and thickness of cortical bone in the mandibular angle can affect the size of GA, and the inclination angle of the mandibular body affects the incident X-ray directly.

Shahabi et al. ${ }^{[31]}$ compared the external gonial angle determined from the lateral cephalograms and panoramic radiographs in Class I patients from the obtained results, they concluded that panoramic radiography can be used to determine the gonial angle .

Studies have reported contradictory results for alveolar heights when comparing subjects with different vertical skeletal patterns. A major source of confusion might stem from the fact that several studies selected the sample based on the dental overbite and did not differentiate

\section{CONCLUSION:}

1. There is a statistically significant relationship between facial type and alveolar height and thickness.

2. Dentoalveolar compensation mechanism acts in both high-angle and low-angle subjects by vertical lengthening of the maxillary and mandibular frontal alveolar process. No significant differences were found for the measurements of alveolar height in the posterior region

3. High-angle group presented thinner alveolus anteriorly in the maxilla and at almost all sites in the mandible. so subjects can be at increased risk of moving incisors beyond alveolar bone support .

4. Clinicians should always keep in mind that mandibular condyles can be asymmetric, so that possibility must be considered when using panoramic radiographs.

5. With standard exposure conditions and high image quality, panoramic radiographs can provide information on the vertical dimensions of craniofacial structures; however, they are not reliable enough to give acceptably accurate additional 


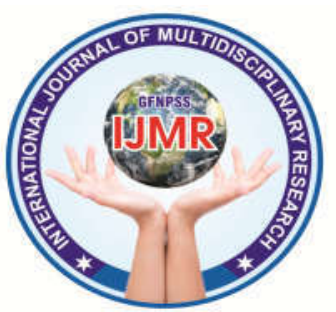

information compared with lateral class 1 malocclusion .J Oral Sci cephalograms. $51,425-29,2009$

6.The vertical measurements were always

03. E.M.Ongkosuwito,et al, Linear magnified between approximately $18 \%$ and $21 \%$. Small differences were observed even if the skull was tilted $15^{\circ}$ posteriorly during one series of exposures. Not unexpectedly, the variation was greatest in the anterior region as reflected by the greater SD

7.Panoramic radiography can be used to determine the gonial angle . Furthermore, in panoramic radiography, the right and left gonial angle scan is measured easily without superimposition of anatomic landmarks, which occurs frequently in a lateral cephalogram.

8.The observations on the precision of vertical dimensions and gonial angle have encouraged us to continue the research with the panoramic machine.

\section{REFERENCES:}

01. Nasila Nohadani and Sabine Ruf ,Assessment of vertical facial and dentoalveolar changes using panoramic radiography,Eur $\mathrm{J}$ orthod 2008;30:262-68

02. Mostafa shahabi, et al, Comparison between the external gonial angle in panoramic radiographs and lateral cephalograms of adult patients with mandibular measurements : Comparison between orthopantomograms and lateral cephalograms Cleft palateCraniofacial Journal,2009;46(2):14753

04. Simanikneshan,et al, Evaluation of the accuracy of linear and angular measurements on panoramic radiographs taken at different positions Imaging sci Dent 2013;1916.

05. Bhullar MK,et al, Comparision of gonial angle determination from cephalograms and orthopantomogram .Indian J Dent 2014;5:123-6.

06. Masao Araki,et al, Comparitive analysis of the gonial angle on lateral cephalometric radiographs and panoramic radiographs .J oral sci 2015;57:373-78.

07. Kumar SS,et al, Comparison of orhopantomogram and lateral cephalogram for mandibular measurements. J Pharm bioall sci 2017;9:S92-5.

08. Shahab Adil, et al, Comparison of the gonial angle measurement on Lateral 


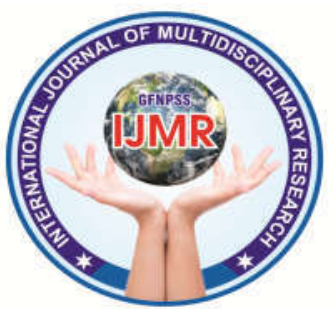

cephalogram and both hemispheres of orthopantomogram. POJ 205: 7 (2) $48-50$

09. Nuran yanikoglu et al.,Radiological evaluation of changes in the gonial angle after teeth extraction.oral and maxillofacial radiology. 2008;105:5560.

10. M. OkanAkcam,TuncAltiok and Erhan Ozdiler ,Panoramic radiographs: A tool for investigating skeletal pattern. Am J Orthod Dentofacial Orthop 2003;123:175-81

11. Mais M. Sadek, Noha E. Sabet and Islam T. Hassan.Alveolar bone mapping in subjects with different vertical facial dimensions. Eur $\mathrm{J}$ Orthod, 2015, 194-201

12. Soonshin Hwang et al.,Threedimensional evaluation ofdentofacial transverse widths in adultswith different sagittal facial patterns . Am JOrthod Dentofacial Orthop 2018;154:365-74

13. Girish Kattiet al,Reliability of panoramic radiography in assessing gonial angle compared to lateral cephalogram in adult patients with Class I malocclusion. J Indian Acad Oral Med Radiol 2016;28:2525
14. T. A. Larheim and D. B. Svanaes, Reproducibility of rotational panoramic radiography: Mandibular linear dimensions and angles AM J ORTHOD DENTOFAC ORTHOP 90: 45-51, 1986

15. Estrella Hernández-Sayago et al.,Lower incisor position in different malocclusions and facial patterns. Med Oral Patol Oral Cir Bucal. (2012),

16. $\mathrm{U} \mathrm{Oz}, \mathrm{K}$ Orhan and $\mathrm{N}$ Abe. Comparison of linear and angular measurements using two dimensional conventional methods and threedimensional cone beam $\mathrm{CT}$ images reconstructed from a volumetric rendering program invivo. Dento maxillo facial Radiology (2011) 40, $492-500$

17. Chang-Seo Park et al., Comparison of conventional lateral cephalograms with corresponding CBCT radiographs. Imaging Sci Dent 2012; $42: 201-5$

18. Dietmar Segner,Floating norms as a means to describe individual skeletal patterns .European Journal of Orthodontics 11 (1989) 214-22

19. Danna Xiao, Hui Gao and Yijin Re : Craniofacial morphological 


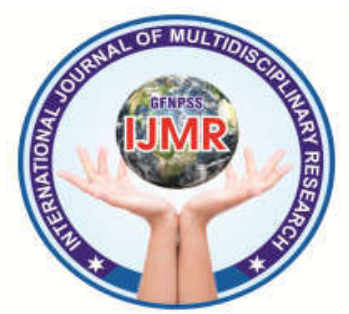

characteristics of Chinese adults with normal occlusion and different skeletal divergence .The European Journal of Orthodontics 13 (2010)

20. Zangouei-Booshehri M, Aghili HA, Abasi M, . Agreement Between Panoramic and Lateral Cephalometric Radiographs for Measuring the Gonial Angle. Iran J Radiol. 2012; 9 (4): 178-82.

21. SukruEnhosa et al., Dehiscence and fenestration in patients with different vertical growth patterns assessed with cone-beam computed tomography. Angle Orthod. 2012;82:868-874.

22. Ridvan Oksayan et al, Does the Panoramic Radiography Have the Power to Identify the Gonial Angle in Orthodontics?. The Scientific World Journal Volume 2012

23. Shigeki Nakajima, Shigeo Osato. Association of gonial angle with morphology and bone mineral content of the body of the adult human mandible with complete permanent dentition Annals of Anatomy 195 (2013) 533- 538

24. keijo mattilda, Mikko Altonen, kaarina haavikko. Determination of gonial angle from orthopantamogram Uni of Helinki, Dept of oral surgery, pedodontics nd orthodontics (1977) Vol.47, No.2

25. Anthony W, Savage, Kevin J. Showfety .Repeated measures analysis of geometrically constructed and directly determined cephalometric points AM J ORTHO DENTOFAC ORTHOP 1987;91:2959.)

26. Ronald G Phillip, Robert V.V Hurst. The Cant of occlusal plane and distortion in the panoramic radiograph Louisiana state university, Dept of orthodontics Oct $1978 \mathrm{Vol}$ 48, No. 4

27. Mauricio Berco,et al, reliability of linear cephalometric measurements from cone-beam computed tomography scans of a dry human skull .Am J Orthod Dentofacial Orthop 2009;136:17.e1-17.e9

28. Beni Solow, The Dentoalveolar Compensatory Mechanism: Background and Clinical Implications*British Journal of Orthodontics/Vol 7/1980/145-161 